\title{
EVALUATION OF IMMUNOCYTOCHEMISTRY ON THE DIAGNOSIS OF PAPILLARY MAMMARY TUMORS BY FINE-NEEDLE ASPIRATION BIOPSY
}

\author{
Avaliação do uso da imunocitoquímica no diagnóstico dos tumores \\ papilares mamários em punção aspirativa de agulha fina
}

Fábio Postiglione Mansani* (D), Marina Bertucci (D), Mário Rodrigues Montemór Netto ${ }^{1}$ (D), Luiz Martins Collaço1 ${ }^{10}$, Jorge Felipe do Lago Pereira dos Santos ${ }^{1}$ (D)

\section{ABSTRACT}

Purposes: This study has observed the effectiveness of the immunocytochemical method on the diagnosis of papillary lesions of the breast from fine needle aspiration biopsy (FNAB), to validate the method that would avoid unnecessary excision of small intraductal papillomas of the breast when applied to clinical practice. Methods: Medical records and FNAB examinations were analyzed from 2003 to 2012 and subsequently a immunocytochemical examination was performed with p63 myoepithelial cell marker and Ki67 proliferative index, analyzing the specificity and sensitivity of the markers in the diagnosis of papillary lesions of the breast. Results: The immunocytochemistry of the papillary breast lesions material with immunomarkers Ki67 and p63 showed sensitivity of $78.6 \%$ and specificity of $73.33 \%$ in the identification of benign lesions. Conclusions: The combined use of these markers in FNAB of papillary mammary lesions helps in the therapeutic orientation of the disease, but further studies including a larger number of cases should be performed in order to have a better evaluation of this method.

KEYWORDS: intraductal papilloma; fine-needle biopsy; immunohistochemistry; Ki-67 antigen; pathology.

\section{RESUMO}

Objetivo: Este estudo observou a efetividade do método imunocitoquímico no diagnóstico das lesões papilares de mama a partir de amostras por punção aspirativa por agulha fina (PAAF), para validar o método que, aplicado à prática clínica, evitaria a exérese desnecessária dos pequenos papilomas intraductais da mama. Métodos: Foram analisados prontuários e exames de PAAF durante o período de 2003 a 2012 e posteriormente realizado exame imunocitoquímico com marcador de célula mioepitelial p63 e índice proliferativo Ki67, analisando-se especificidade e sensibilidade dos marcadores no diagnóstico de lesões papilares da mama. Resultados: A imunocitoquímica dos materiais das lesões papilares mamárias com os imunomarcadores Ki67 e p63 apresentou sensibilidade de $78,6 \%$ e especificidade de $73,33 \%$ na identificação das lesões benignas. Conclusões: $O$ uso combinado desses marcadores em PAAF de lesão papilar mamária auxilia na orientação terapêutica da doença, mas novos estudos incluindo um maior número de casos devem ser realizados para melhor avaliar esse método.

PALAVRAS-CHAVE: papiloma intraductal; biópsia por agulha fina; imuno-histoquímica; antígeno Ki-67; patologia.

${ }^{1}$ Universidade Estadual de Ponta Grossa (UEPG) - Ponta Grossa (PR), Brazil.

*Corresponding author: mansanifp@gmail.com

Conflicts of interest: nothing to declare.

Received: 08/16/2017. Accepted: 05/11/2018 


\section{INTRODUCTION}

The papillary lesions of the breast represent about $0.5 \%$ of all breast tumor diagnoses ${ }^{1}$ and may be benign or malignant, but all are characterized by the presence of a fibrovascular center lined by epithelial proliferation with varying degrees of atypia (Figure 1$)^{2}$.

The diagnosis of breast lesions, in general, is determined by the anatomopathological report, clinic and image triad. In this context, the fine needle aspiration biopsy (FNAB) plays an important role in the evaluation of these lesions, since it is a simple, fast, cheap and reliable method to obtain material for analy$\mathrm{sis}^{2}$. However, there is great statistical variability, since a study based on 31,340 punctures observed a sensitivity varying from 65 to $98 \%$ and a specificity ranging from 34 to $100 \%$, although it can be explained by changes in the quantity and quality of the sample, as well as changes in the evaluation of the pathologist ${ }^{3}$.

This is due to the overlap of cytopathological features between benign and malignant entities, as well as other lesions containing papillary component. Some features such as cellularity, complex fragments of papillary lesions with complex ramifications and intact atypical cells point to a malignant nature of the tumor ${ }^{4,5}$.

Although the radiological and clinical-surgical studies are of fundamental importance, the anatomopathological report is the gold standard that closes the diagnosis of the mammary lesion. Immunocytochemistry (ICQ) is often mandatory in the differential diagnosis between benign and malignant lesions ${ }^{6}$.

Several markers can be used for breast tumors. In this work we used p63, a nuclear protein expressed in the basal epithelium of several organs, which in the breast has its positivity close to $100 \%$, when the extracellular matrix is normal and in benign proliferative lesions; and Ki67, a protein whose function is associated with cell replication, staining nuclei at any stage of the cell cycle except $\mathrm{G} 0^{7-10}$.

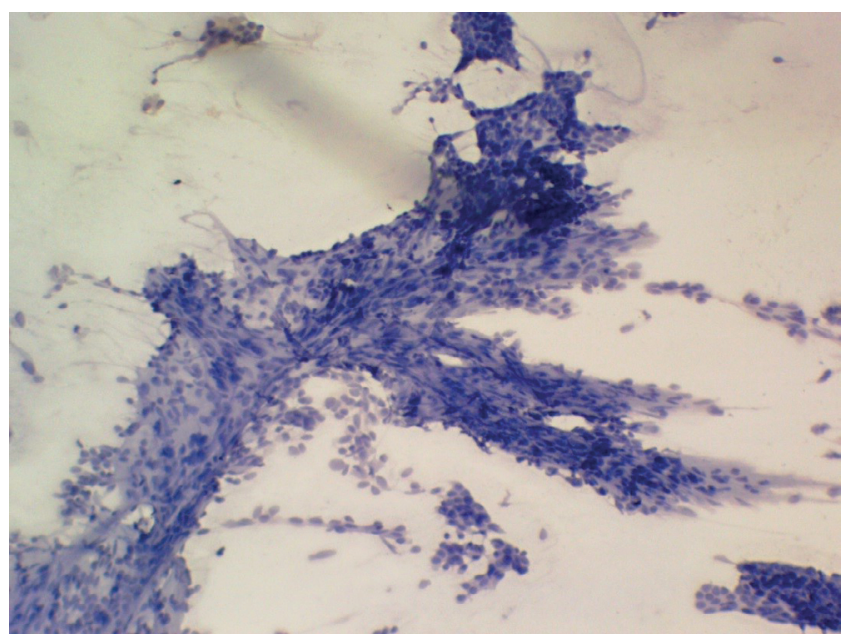

Figure 1. Panoramic photomicrograph of papillary lesion demonstrating arborescent connective axis with partial lining by epithelial cells.
The study proposed to observe the effectiveness of the ICQ method in this differential diagnosis and, if positive, it will be able to validate the method that would avoid unnecessary excision of the small intraductal papillomas of the breast and would aid in the therapeutic planning of papillary carcinoma, when applied to clinical practice, avoiding additional surgeries and reducing local morbidity.

\section{METHODOLOGY}

This is a retrospective study to analyze cases diagnosed with papillary lesion of the breast (mammary papilloma, intraductal papillary carcinoma/in situ, papillary carcinoma), which have preoperative FNAB evaluations available at the breast cytopathology database of the Laboratory of Medical Pathology (Laboratório de Patologia Médica, Ponta Grossa, Paraná) and medical records in the Institute of Oncology Sul Paranaense (Instituto Sul Paranaense de Oncologia, Ponta Grossa, Paraná) from 2003 to 2012. An ICQ examination with p63 myoepithelial cell marker and Ki67 proliferative index was performed on the FNAB blades recorded in the institution, which had previously been stained by the Pap smear. Based on the medical records, the following information was obtained and used to analyze possible correlations: age, family history of neoplasms, history of hormone replacement therapy and radiological classification (BI-RADS) of the lesion (by mammography or ultrasonography).

An ICQ examination for Ki67 and p63 of the papillary lesions was performed by the detection method ADVANCE TM HRP (DAKO Code K4068), on silanized and manually processed slides. Antigenic recovery was carried out in a water bath at $98^{\circ} \mathrm{C}$ in citrate buffer BIOSB for 40 minutes, when necessary. The incubation method of the primary antibody for 2 hours at room temperature $\left(20\right.$ to $\left.25^{\circ} \mathrm{C}\right)$ and the DakoCytomation development system (DAB + chromogen) were used. Expression of Ki67 and p63 was considered positive when they had more than 10 and $25 \%$ of stained positive nuclei, respectively ${ }^{11-13}$

After evaluating the data obtained through the ICQ in the interpretation of the responsible pathologist, comparing the diagnoses present in the anatomicopathological reports of the surgical wards (gold standard), the diagnostic performance measures were calculated for: sensitivity, specificity, positive and negative predictive values, and accuracy of the complementary method employed, evaluating its diagnostic applicability in clinical practice. Non-parametric Kruskal-Wallis test was used for comparison of means between benign, atypical and malignant lesions; the non-parametric Mann-Whitney test for comparison of means between benign and atypical/malignant grouped lesions; and Fisher's exact test for determination of diagnostic performance measures.

The cases selected meet the inclusion criteria: diagnosis of papillary lesion of the breast (mammary papilloma, intraductal 
papillary carcinoma/in situ, papillary carcinoma), with preoperative FNAB evaluations available at the breast cytopathology database of the Laboratory of Medical Pathology of Ponta Grossa from 2003 to 2012.

Exclusion criteria were: unavailability of a slide for ICQ, unavailability of the anatomopathological report or report not corresponding to papillary lesion, patients whose blades of FNAB were stained only by the Giemsa method and cases when all the slides of the preoperative anatomopathological examinations are considered unsatisfactory in the evaluation of the pathologist of the laboratory of pathological anatomy.

\section{RESULTS}

The analysis of the database of the Laboratory of Medical Pathology of Ponta Grossa located 49 cases that presented preoperative cytological diagnosis by FNAB of papillary tumor. Following the exclusion criteria described in the research method, 8 cases were excluded due to delayed analysis of the material and 12 cases because they did not have an accessible anatomopathological examination. Therefore, 29 cases, with 33 lesions, were statistically analyzed. The cases occurred between 2003 and 2012.

In the studied group, all the cases (100\%) are female and present mean age of 50.4 years, with a standard deviation of 13.1. Age ranged from 32 to 82 years, and the median age was 48 years.

The lesions identified were categorized into 3 groups, based on the definitive diagnosis obtained by the anatomopathological examination of the surgically removed mammary segments: 15 benign, with 2 of them belonging to the same patient and bilateral (45\%); 14 atypical (43\%), with 3 in the same patient and in the same breast; and 4 malignant ones (12\%).

Lesions were located in the left breast in 18 patients (62\%), in the right breast, in 8 (27.5\%); and in 2 cases (7\%) there was bilateral involvement of the breasts. The information regarding one patient (3.5\%) was missing.

The mean age in cases of malignant and atypical lesions was 51.9 years, higher than the mean of 46 years for benign lesions $(p=0.16)$. When compared separately, malignant lesions had a significantly longer mean age of 65 years ( $p=0.04$; by the Kruskal-Wallis test).

In 12 cases (41.3\%), a positive family medical history was found for neoplasms. In 13 cases (45\%), there was a negative history; and it was not possible to find the information in 4 cases (13.7\%). The history was positive in $66.6 \%$ of cases diagnosed with malignant/atypical lesions and in $33.4 \%$ of patients with benign lesions ( $\mathrm{p}=0.15$, by Fisher's exact test).

The hormone replacement therapy for the treatment of climacteric syndrome was being performed in 4 patients (13.8\%) at the time of diagnosis.

The radiological evaluation(Figure 2) by mammography showed suspicious results for malignancy (corresponding to BI-RADS classifications 4A, 4B and 4C) in 8 cases (27.6\%), while breast ultrasonography detected 24 cases with suspicious results (82.9\%).

The distribution of nodular lesions in the mammary gland showed 11 cases in the central portion, 6 benign and 5 malignant ones; 11 cases in lateral quadrants and 6 cases in the middle quadrants, and 5 lesions were not specified in the medical record. Of all peripheral lesions, 11 were malignant and 6 were benign. This pattern shows more frequent malignant lesions in the peripheral quadrants, as well as benign lesions in the central portion of the breast.

The papillary lesions studied in the breast ultrasonography showed an average diameter of $1.2 \mathrm{~cm}$; benign lesions, mean diameter of $1.17 \mathrm{~cm}$; lesions with atypia, mean diameter $0.97 \mathrm{~cm}$; and malignant ones, mean diameter of $1.92 \mathrm{~cm}$. When data of the atypical and malignant lesions were grouped, a mean diameter of $1.21 \mathrm{~cm}$ was obtained, which, when compared to the values of benign lesions, did not show statistical significance ( $p=0.88$, Mann-Whitney parametric test).

In the analysis of the ICQ results, patients were divided into two groups according to the anatomopathological diagnosis of the surgical specimen after resection: benign lesions and atypical and malignant ones.

When the Ki67 results were separated into nuclear percentage bands and the results were analyzed by grouping atypical and malignant lesions, in comparison with benign lesions, a high significance was observed ( $p=0.002$; by Fisher's exact test), with greater expression of the marker in the grouped non-benign ones(Table 1).

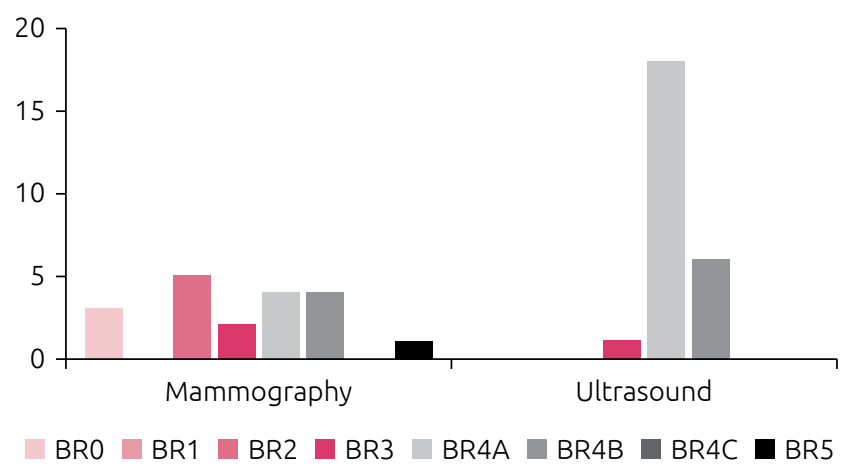

Figure 2. Classification of lesions in radiological examinations.

Table1. Correlation between Ki67 positivity and immunohistochemical/anatomopathological diagnosis

\begin{tabular}{l|c|c} 
Table of Content & Atypical and malignant & Benign \\
\hline $1(<10 \%)$ & 8 & 14 \\
\hline $2(10$ to $25 \%)$ & 4 & 0 \\
\hline $3(25$ to $50 \%)$ & 4 & 0 \\
\hline
\end{tabular}


Ki67 was thought to be positive from the $\geq 10 \%$ index, negative in all benign lesions, which never exceeded this cut, and in 8 cases in the group with atypical and malignant lesions, corresponding to $50 \%$. In the group of cases with atypical and malignant lesions, 8 cases were Ki67 positive. In the isolated analysis, it was observed that $100 \%$ of the malignant cases were Ki67 positive.

By relating atypical/malignant and benign lesions, we obtained a mean Ki67 positivity of $14.4 \%$ for the former; and $3 \%$ for the benign ones ( $p=0.003$; for Mann-Whitney), with a median of $10.5 \%$ for the positives and $2 \%$ for the negatives.

The estimated sensitivity of Ki67 was 50\% (probability of a positive result in Ki67, given that the lesion was malignant/atypical). The estimated specificity of Ki67 was $100 \%$ (probability of a negative result in Ki67 because the lesion was benign) ( $p=0.002$; Fisher's exact test).

The ICQ with the use of p63 for labeling myoepithelial cells is shown in Figure 3. Mean positivity of 63 was observed in benign lesions of $33.6 \%$, whereas in atypical/malignant lesions the mean was $23.1 \%$ ( $p=0.16$, by the Mann-Whitney test).

The ICQ performed in isolated cells and in cell clusters presented the same result. P63 was positive in 11 benign lesions and 7 atypical/malignant ones, and negative in 3 benign lesions and 10 atypical/malignant ones $(p=0.04$; by Fisher's exact test).

The estimated sensitivity of p63, that is, the probability of obtaining a " $>25 \%$ " result with a benign lesion, was $78.6 \%$, and its estimated specificity, that is, probability of a " $<25 \%$ " outcome with malignant/atypical lesion, was $58 \%$.
A joint analysis of the ICQ of Ki67 and p63 was performed, showing all benign cases with Ki67 negative, but not all of them were p63 positive. The probability of benign lesions being Ki67 negative and p63 positive, that is, the sensitivity, is $78.6 \%$. The probability of atypical/malignant lesions being different from this standard, that is, the specificity, is $73.33 \%$ ( $p=0.007$; Fisher's exact test).

The analysis revealed atypical/malignant cases in $26.7 \%$ with Ki67 positive and p63 negative, 20\% with Ki67 and p63 positive, $26.7 \%$ with Ki67 negative and p63 positive, and in $26.6 \%$ of cases with Ki67 and p63 negative (Table 2).

The existence of a relationship between the two markers was evaluated and an inverse correlation was observed between the expression of Ki67 and p63, with coefficient $r^{2}=-0.55$, but without statistical significance $(\mathrm{p}=0.19)$. With increasing Ki67 expression, there is a decrease in p63 expression.

Table 2. Joint analysis of Ki67e p63 expression in comparison to the immunohistochemical/anatomopathological diagnosis.

\begin{tabular}{|c|c|c|c|c|c|}
\hline & . . & $\frac{\overrightarrow{0}}{\frac{0}{a}}$ & 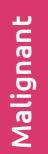 & 点 & 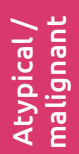 \\
\hline Ki67- and p63+ & 11 & 4 & 0 & 11 & 4 \\
\hline Ki67+ and p63+ & 0 & 3 & 0 & 0 & 3 \\
\hline Ki67+ and p63- & 0 & 0 & 4 & 0 & 4 \\
\hline Ki67- and p63- & 3 & 4 & 0 & 3 & 4 \\
\hline Total & 14 & 11 & 4 & 14 & 15 \\
\hline
\end{tabular}
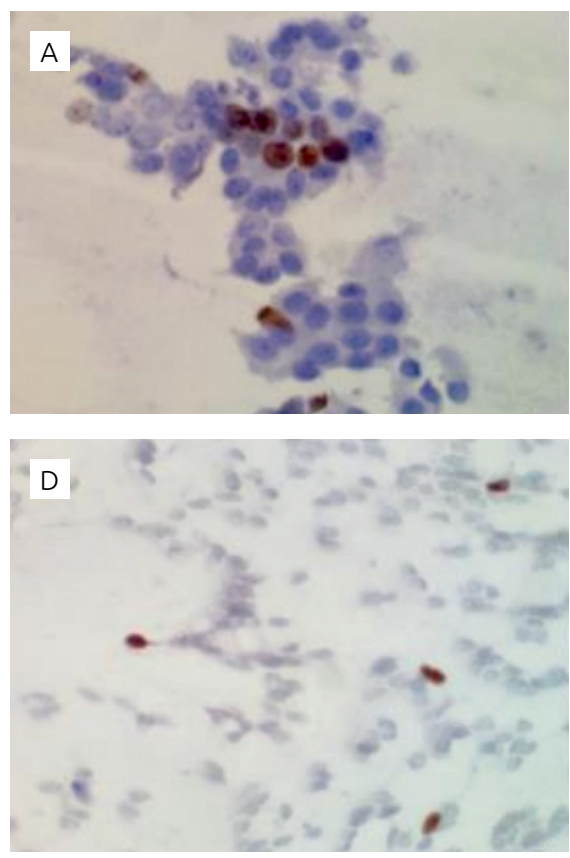
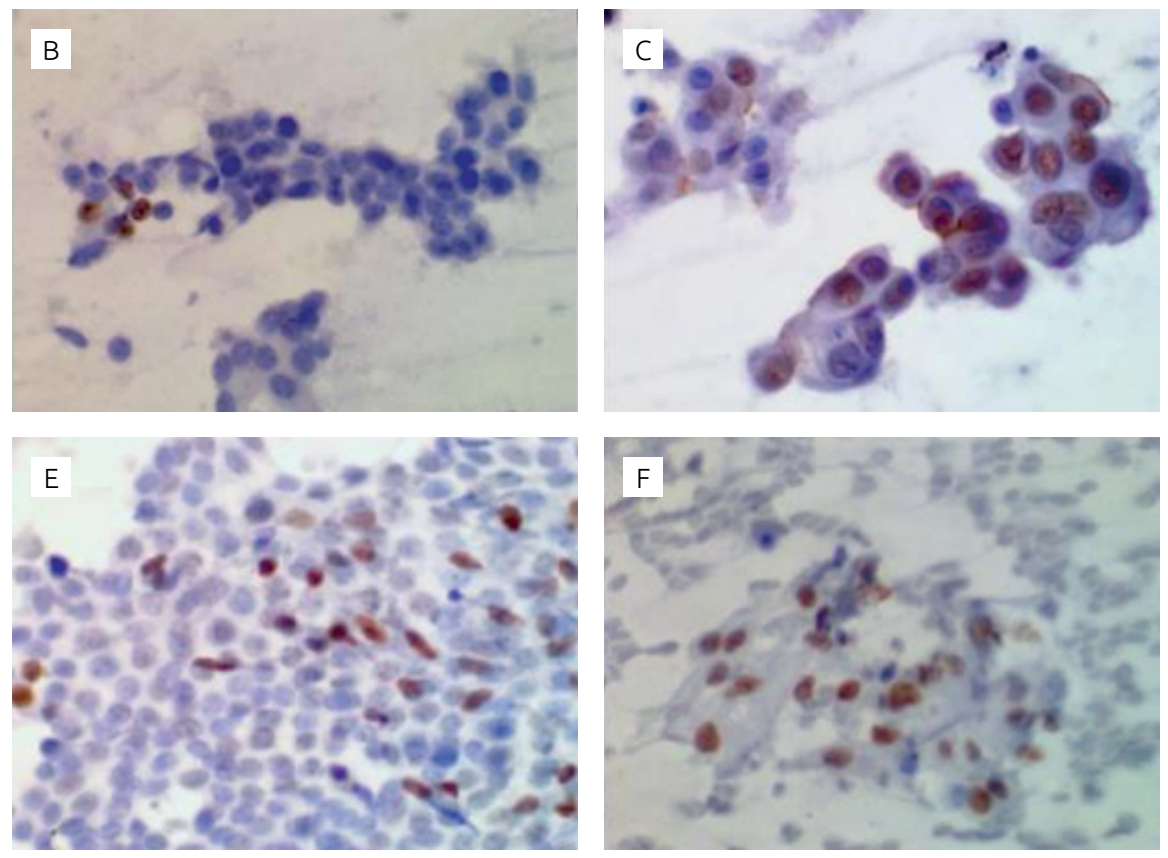

Figure 3. Demonstration of Ki67 and p63 marking. (A) Ki67 (18\%; 74 cells, 14 marked); (B) Ki67 (5\%; 80 cells, 4 marked);

(C) Ki67 (54\%; 37 cells, 20 marked); (D) p63 (5\% isolated cells); (E) p63 (10\% clusters marked); (F) p63 (80\% clusters marked). 


\section{DISCUSSION}

The diagnostic confirmation of papillary breast lesions, both by FNAB and by core or transoperative biopsy, is difficult to perform ${ }^{4}$. This difficulty led to the search for a new method that would allow to distinguish cases that required surgical excision or that could be followed in a conservative way; ICQ was promising in this context ${ }^{14}$.

The study analyzed 2,777 breasts on FNAB from the database of the medical pathology, and found 56 cases of papillary lesion. 15 cases were excluded due to delayed analysis of the material and 6 cases because they did not have an accessible anatomopathological examination. This number reflects $2 \%$ of the lesions, corresponding to the statistics found in the literature, described as $<10 \%$ of breast lesions and $<1 \%$ of breast carcinomas ${ }^{15}$.

The cases were divided into three groups in order to facilitate data analysis: benign lesions, atypical lesions and malignant lesions, with atypical lesions being grouped with malignant lesions, since both have an indication of surgical removal. The distribution of atypical, malignant and benign cases showed statistical similarity with the reviewed literature, with $46 \%$ benign, $43 \%$ atypical and $12 \%$ malignant ${ }^{16,17}$.

The age analysis of the patients showed an average of 50.4 years; the mean in benign lesions (46 years) is lower and in malignant lesions (65 years) is higher, according to previous reviews ${ }^{18-21}$.

The analysis of hereditary morbid history for breast carcinoma was unrelated to the results of the anatomopathological study, which corresponds to the one found in the reviews on the subject ${ }^{22}$.

Most of the lesions were found in the left breast (62\%). When the distance of the lesion from the nipple was analyzed, benign lesions were predominant in the central portion and malignant ones in the peripheral portion. These data were considered foreseeable in relation to previous studies ${ }^{21-23}$.

According to the results of imaging diagnosis, mammography detected only 8 nodules (27.6\%), and breast ultrasonography detected 24 (82.9\%), showing greater effectiveness of this examination. A total of $72.7 \%$ of diagnoses were classified as BI-RADS 4. Mammography did not detect papillary breast lesions at present, and tumors were of medium-sized progressive diameter between benign, atypical and malignant lesions ${ }^{17,23,24}$.

ICQ was the preferred method for preoperative assessment of papillary lesions was the ICQ, and the markers selected were p63 and Ki67. The first is a nuclear protein expressed in the basal epithelium of various organs, with its positivity close to $100 \%$ in the breast when the extracellular matrix is normal and in benign proliferative lesions. Advantages include its nuclear staining pattern, excluding cross-reaction with myofibroblasts, present in many other markers, its absence of vessel reactivity, as well as its high sensitivity , 22-24. $^{2}$.

However, the isolated determination of myoepithelial cells by ICQ is not sufficient to separate benign and malignant papillary lesions. Thus, in order to increase the accuracy of the FNAB method associated with ICQ, a marker was added for detection of lesion epithelial proliferation, selecting Ki67, which is a protein whose function is associated with cell replication, staining nuclei at any stage of the cycle of the cell, except G0. Its role in regulating the cell cycle and a short half-life establishes this protein an important marker of proliferating cells ${ }^{25}$.

The Ki67 protein is absent in quiescent cells (G0) and is universally expressed in proliferating cells. These are advantages attributable to the possibility of distinguishing between the marker-able cell types, and thus, it is possible to differentiate a Ki67-producing inflammatory cell from a tumor cell, and because it is an inexpensive method, it can easily be included in the diagnostic routine ${ }^{8,21}$.

Although there is a relationship that allows the separation of benign lesions expressing myoepithelial cell markers and malignant lesions in which these cells are absent or rarely detected, there is no reliable relationship between the results of preoperative percutaneous biopsies and the result of the anatomopathological exam of the surgical specimen. Both due to problems in the expression of the ICQ marker and in the sample collected, which may not include all the lesion to be analyzed. Moreover, there are analysis variations that depend on the experience of the pathologist.

The positivity of the p63 marker is considered to be greater than $1+$ (greater than or equal to $25 \%$ of the cells stained by ICQ). The high sensitivity of p63 in benign papillary lesions (78.57\% in this study) was not sufficient to separate the benign lesions that could be only accompanied, from atypical/malignant ones, due to the low specificity of the method (58.82\%).

The results found in Ki67 determination agreed that all benign lesions showed expression below the cutoff plane ( $10 \%$ of the cells marked by the immunomarker). When the atypical/malignant cases were analyzed, this separation was not so clear, since $53 \%$ of these lesions were negative for Ki67. However, when analyzed alone, $100 \%$ of the malignant lesions were positive for Ki67. When Ki67 expression data on the slides were tabulated using the absolute proportional numbers of positive cells, this difference in expression between benign and atypical/malignant lesions showed high statistical significance, which demonstrates the applicability of the method.

Ki67 in papillary mammary lesions showed sensitivity of $50 \%$ and specificity of $100 \%$, but did not allow the safe separation between benign and atypical/malignant lesions for the purpose of definitive conduct.

P63 and Ki67 data presented in this study reinforced the statements of a large part of the authors, who affirm that the use of isolated markers is not sufficiently selective to separate benign from malignant and atypical lesions ${ }^{10-12}$.

The ICQ profile of benign lesions was $78.6 \%$ positive for benign p63 cases and 100\% negative for Ki67 expression, and the proven 
malignant lesions in the surgical pathology samples also showed a 100\% correlation with ICQ with negative p63 and positive Ki67. This inverse association with the markers under study, in which the greater the expression of 63 the lower the one of Ki67 and vice versa, analyzed a statistical correlation study of statistical significance.

Difficulties were observed in the interpretation of the data of atypical or of uncertain behavior lesions, which are part of the study material. Of these lesions, $36.4 \%$ presented the same profile of benign lesions (positive p63 and negative Ki67), and when atypical and malignant lesions were grouped together, this rate was reduced to $26.7 \%$.

In the analysis of the results, the association of p63 with Ki67 in FNAB of papillary mammary lesions showed 100\% sensitivity and specificity for malignant lesions. When the sensitivity for diagnosis of benign lesions was analyzed using this same association of immunomarkers, the result was $78.6 \%$, but with specificity of $73.33 \%$.

When the information obtained in the study were transferred to the clinical context, there were some difficulties. The study found that the $\mathrm{p} 63$ positive and Ki67 negative profiles contained all benign cases, but also $26.7 \%$ of the lesions of the atypical $/$ malignant group, therefore, when a conservative treatment was proposed, these lesions of uncertain behavior would not be resected.

When the study evaluated the aid of ICQ in the conduct of papillary lesions diagnosed by FNAB, it was observed that, when proposing appropriate action for lesions with malignant profile, these patients would be exaggeratedly treated in $25 \%$ of the cases, represented by atypical lesions, which would receive treatment for malignant neoplasm of the breast. However, by choosing to follow only those who presented a benign profile to ICQ, we would no longer treat $26.7 \%$ of patients with atypical or uncertain behavior, which would be better conducted by complete resection of the lesion.
Therefore, cases with ICP profiles in FNAB of papillary lesions with negative Ki67 and positive p63 could be closely monitored with clinical evaluation and imaging tests, but only in special situations and with the express agreement of the patients.

Regarding the surgical approach, patients with positive Ki67 and negative $\mathrm{p} 63$ profiles should be considered as probably malignant and treated with rigorous oncological criteria. Other patients with other Ki67 and p63 associations may undergo simple nodule excision, since they do not include malignant lesions. Although FNAB of papillary mammary lesions of ICQ profile with Ki67 and p63 help in the therapeutic orientation of these patients, they would be better evaluated with surgical removal to avoid damage to the necessary treatment.

Due to the small number of cases included in this study, new trials need to be performed with a greater number of lesions in order to obtain a statistical representation that allows the safe evaluation of the method.

\section{CONCLUSIONS}

It may be concluded by the present study that most of the benign lesions were located in the central region of the breast, while atypical and malignant lesions were predominantly located in peripheral quadrants.

Ultrasound showed to be more effective than mammography in identifying papillary mammary lesions and the analysis of the ICQ study of papillary mammary lesion materials with the Ki67 and p63 immunomarkers showed sensitivity of $78.6 \%$ in the detection of benign lesions and specificity of $73.33 \%$.

The combined use of these markers in FNAB of papillary mammary lesions helps in the therapeutic orientation of the disease, but further studies including a larger number of cases should be performed to better evaluate this method.

\section{REFERENCES}

1. Pal SK, Lau SK, Kruper L, Nwoye U, Garberoglio C, Gupta RK, et al. Papillary carcinoma of the breast: an overview. Breast Cancer Res Treat.2010;122(3):637-45.https://doi.org/10.1007/s10549-010-0961-5

2. Willems SM, van Deurzen CHM, van Diest PJ. Diagnosis of breast lesions: fine-needle aspiration cytology or core needle biopsy? A review. J Clin Pathol. 2012;65(4):287-92. http://dx.doi. org/10.1136/jclinpath-2011-200410

3. Frankel PP, Esteves VF, Thuler LCS, Vieira RJ da S. Acurácia da punção aspirativa por agulha fina e da punção por agulha grossa no diagnóstico de lesões mamárias. Rev Bras Ginecol Obs. 2011;33(3):139-43. http://dx.doi.org/10.1590/ S0100-72032011000300007

4. Aggarwal D, Soin N, Kalita D, Pant L, Kudesia M, Singh S. Cytodiagnosis of papillary carcinoma of the breast: Report of a case with histological correlation. J Cytol. 2014;31(2):119-21. https://dx.doi.org/10.4103\%2F0970-9371.138694

5. Gobbi H. Classificação dos tumores da mama: atualização baseada na nova classificação da Organização Mundial da Saúde de 2012. J Bras Patol Med Lab. 2012;48(6):463-74. http:// dx.doi.org/10.1590/S1676-24442012000600013

6. Zhao L, Yang X, Khan A, Kandil D. Diagnostic Role of Immunohistochemistry in the Evaluation of Breast Pathology Specimens. Arch Pathol Lab Med. 2014;138(1):16-24. https:// doi.org/10.5858/arpa.2012-0440-RA

7. Dewar R, Fadare O, Gilmore H, Gown AM. Best practices in diagnostic immunohistochemistry: Myoepithelial markers in breast pathology. Arch Pathol Lab Med. 2011;135(4):422-9. https://doi.org/10.1043/2010-0336-CP.1 
8. Aikawa E, Kawahara A, Kondo K, Hattori S, Kage M. Morphometric analysis and p63 improve the identification of myoepithelial cells in breast lesion cytology. Diagn Cytopathol. 2010;39(3):172-6. https://doi.org/10.1002/dc.21353

9. Hafez NH, Tahous NS. The Role of P63 Immunocytochemistry for Myoepithelial Cells in the Diagnosis of Atypical and Suspicious Cases in Breast Fine Needle Aspiration Cytology (FNAC). J Egypt Natl Canc Inst. 2010;22(2):123-34.

10. Reisenbichler ES, Adams AL, Hameed O. The Predictive Ability of a CK5/p63/CK8/18 Antibody Cocktail in Stratifying Breast Papillary Lesions on Needle Biopsy: An Algorithmic Approach Works Best. Am J Clin Pathol. 2013;140(6):767-79. https://doi. org/10.1309/AJCPXV64GXLZCIGA

11. Parthasarathi K. Ki-67: a review of utility in breast cancer. Aust Med Student J. 2015;6(1):102-4.

12. Zaha DC. Significance of immunohistochemistry in breast cancer. World J Clin Oncol. 2014;5(3):382-92. https://dx.doi. org/10.5306\%2Fwjco.v5.i3.382

13. Al-Maghraby H, Ghorab Z, Khalbuss W, Wong J, Silverman JF, Saad RS. The diagnostic utility of CK5/6 and p63 in fine-needle aspiration of the breast lesions diagnosed as proliferative fibrocystic lesion. Diagn Cytopathol. 2012;40(2):141-7. https:// doi.org/10.1002/dc.21534

14. Tse GM, Ni Y-B, Tsang JYS, Shao M-M, Huang Y-H, Luo M-H, et al. Immunohistochemistry in the diagnosis of papillary lesions of the breast. Histopathology. 2014;65(6):839-53. https://doi.org/10.1111/his.12453

15. Boin DP, Baez JJ, Guajardo MP, Benavides DO, Ortega ME, Valdés DR, et al. Breast papillary lesions: an analysis of 70 cases. Ecancermedicalscience. 2014;8:461. https://dx.doi. org/10.3332\%2Fecancer.2014.461

16. Wiratkapun C, Keeratitragoon T, Lertsithichai P, Chanplakorn N. Upgrading rate of papillary breast lesions diagnosed by core-needle biopsy. Diagnostic Interv Radiol. 2013;19:371-6. https://dx.doi.org/10.5152/dir.2013.017
17. Bianchi S, Bendinelli B, Saladino V, Vezzosi V, Brancato B, Nori J, et al. Non-Malignant Breast Papillary Lesions - B3 Diagnosed on Ultrasound - Guided 14-Gauge Needle Core Biopsy: Analysis of 114 Cases from a Single Institution and Review of the Literature. Pathol Oncol Res. 2015;21(3):535-46. https://doi. org/10.1007/s12253-014-9882-7

18. Prathiba D, Rao S, Kshitija K, Joseph L. Papillary lesions of breast: An introspect of cytomorphological features. J Cytol. 2010;27(1):12-5. https://doi.org/10.4103/0970-9371.66692

19. Moon HJ, Jung I, Kim MJ, Kim E-K. Breast Papilloma without Atypia and Risk of Breast Carcinoma. Breast J. 2014;20(5):525-33. https://doi.org/10.1111/tbj.12309

20. Jagmohan P, Pool FJ, Putti TC, Wong J. Papillary lesions of the breast: imaging findings and diagnostic challenges. Diagn Interv Radiol. 2013;19(6):471-8. https://doi.org/10.5152/dir.2013.13041

21. Choi SH, Jo S, Kim D-H, Park JS, Choi Y, Kook S-H, et al. Clinical and Imaging Characteristics of Papillary Neoplasms of the Breast Associated with Malignancy: A Retrospective Cohort Study. Ultrasound Med Biol. 2014;40(11):2599-608. https://doi. org/10.1016/j.ultrasmedbio.2014.06.018

22. Menes TS, Rosenberg R, Balch S, Jaffer S, Kerlikowske K, Miglioretti DL. Upgrade of high-risk breast lesions detected on mammography in the Breast Cancer Surveillance Consortium. Am J Surg. 2014;207(1):24-31. https://doi.org/10.1016/j.amjsurg.2013.05.014

23. Kuzmiak CM, Lewis MQ, Zeng D, Liu X. Role of Sonography in the Differentiation of Benign, High-Risk, and Malignant Papillary Lesions of the Breast. J Ultrasound Med. 2014;33(9):1545-52. https://doi.org/10.7863/ultra.33.9.1545

24. Kestelman FP, Gomes CFA, Fontes FB, Marchiori E. Imaging findings of papillary breast lesions: A pictorial review. Clin Radiol [Internet]. 2014;69(4):436-41. https://doi.org/10.1016/j. crad.2013.11.020

25. Pathmanathan N, Balleine RL. Ki67 and proliferation in breast cancer. J Clin Pathol. 2013;66(6):512-6. https://doi.org/10.1136/ jclinpath-2012-201085 